OPEN ACCESS

Edited by:

G. M. Shafiullah

Murdoch University, Australia

Reviewed by:

Minh Quan Duong,

The University of Danang, Vietnam

Zhengmao Li,

Nanyang Technological University,

Singapore

Rui Wang,

Northeastern University, China

*Correspondence:

Hong Fan

fan_honghong@126.com

Specialty section:

This article was submitted to

Smart Grids,

a section of the journal

Frontiers in Energy Research

Received: 14 December 2020

Accepted: 13 December 2021

Published: 12 January 2022

Citation:

Fan H, Wang C, Liu L and Li X (2022)

Review of Uncertainty Modeling for

Optimal Operation of Integrated

Energy System.

Front. Energy Res. 9:641337.

doi: 10.3389/fenrg.2021.641337

\section{Review of Uncertainty Modeling for Optimal Operation of Integrated Energy System}

\author{
Hong Fan ${ }^{1 *}$, Cuiying Wang ${ }^{1}, \mathrm{Lu}_{\mathrm{Li}}{ }^{2}$ and Xuan $\mathrm{Li}^{3}$ \\ ${ }^{1}$ Department of Electrical Engineering, Shanghai University of Electric Power, Shanghai, China, ${ }^{2}$ Key Laboratory of Control of \\ Power Transmission and Conversion of Ministry of Education, Shanghai Jiao Tong University, Shanghai, China, ${ }^{3}$ State Grid \\ Economic and Technological Research Institute Co., Ltd., Beijing, China
}

The operation of the integrated energy system will be affected by uncertainties, leading to sub-optimal design decisions. Accurate and effective modeling of these uncertainties is essential to ensure the optimal integration of renewable energy in the integrated energy system. This article first gives the basic optimal operation model of the integrated energy system, and analyzes various uncertain factors in the optimal operation of the integrated energy system. The source side mainly considers the intermittent and volatility of renewable energy output. The load side mainly considers the uncertainty of load forecast errors. The network side mainly considers the characteristics of equipment under variable conditions, equipment failures, and the uncertainty of the coupling of multi-energy flow systems. The energy storage side mainly considers the uncertainty of mobile energy storage grid connection and virtual energy storage participation in demand response. The multi-energy trading market mainly considers the uncertainty of market trading methods and market operation mechanisms. Then, various integrated energy system uncertainty modeling techniques and solving methods are summarized. Finally, it looks forward to the future research directions and challenges faced by the optimal operation of the integrated energy system under the influence of uncertainty.

\section{Keywords: integrated energy system, optimal operation, influencing factors, modeling under uncertainty, solution} methods

\section{INTRODUCTION}

With the increasing energy crisis and environmental pollution, it is an inevitable trend to make full use of renewable energy. The 2019 World Energy Outlook issued by the U.S. Energy Information Administration (EIA) mentioned that the proportion of new energy power generation will increase from 18 to 31\% between 2018 and 2050 (U.S. Department of Energy, 2019). However, the randomness and volatility of renewable energy have brought huge challenges to the safe operation of traditional power systems and market supervision. In order to achieve the long-term goal of a safe, reliable and economical operation of the renewable energy access system, the flexibility of system operation must be improved. In order to solve this problem, domestic and foreign scholars have successively proposed the concepts of Energy Internet (EI) (Sun et al., 2015) and integrated energy system (IES), and strive to build a future energy system that is interconnected, interactive, and equally shared.

As the physical carrier of EI, IES relies on advanced information and communication (ICT), energy conversion and optimized control technology to establish a corresponding coupling relationship between different energy subsystems such as electricity, gas, heat, and cold. It has 
broken the traditional energy system planning and operation limited to a single energy form, maximized the multi-energy synergy and complementary benefits, and improved the energy utilization efficiency and the level of renewable energy consumption (Clegg and Mancarella, 2016; Hong et al., 2018).At present, the optimization research of IES is mainly divided into the following aspects: the optimized operation model that considers the difference of energy flow, the optimized operation model that considers system flexibility, and the optimized operation model that considers the influence of uncertainty. Reference (Li et al., 2020a; Xu et al., 2021) summarized a dynamic optimization method that considers the multi-energy flow of the Energy Internet under the time scale and space scale. Reference (Chen et al., 2020a; Dai et al., 2021) summarized that the resources such as demand response and energy storage are used to improve the operational flexibility of IES. With the continuous increase in the penetration rate of renewable energy, the diversification of user electricity demand and the increase in network complexity, IES is inevitably affected by uncertainty. Uncertainty can be defined as any deviation from the ideal state of the actual system operating with complete deterministic knowledge (Roldán et al., 2019). The randomness of renewable energy power generation, load forecast errors, equipment failures and the characteristics of equipment variable conditions, the impact of environmental changes, market rules, and the evolution of energy prices make uncertain factors critical. Although in some cases, a large amount of data can be obtained to reduce the impact of uncertainty, it is difficult to completely eliminate all its manifestations. Therefore, it has important practical significance to optimize the operation based on the uncertain factors. However, due to the complexity of the model, the intensity of calculation and the time pressure to generate the corresponding strategy, most IES operate in a deterministic manner.

There are still some challenges in considering uncertain factors to achieve optimal operation of IES. Firstly, IES introduces more sources of uncertainty and increases the complexity of scheduling. Edenhofer et al. (2006) divided the uncertainty into two types: model parameter uncertainty and model structure uncertainty. Model parameter uncertainty is caused by the lack of experience related to model parameters, and model structure uncertainty refers to the uncertainty of the model equation itself. The uncertainty of model parameters is the focus of this paper. For example, the uncertainty of renewable energy, electricity prices and heat demand cannot be ignored in IES. Secondly, with the transition to a fully renewable energy system, it is more challenging to optimize operation under uncertainty in terms of uncertainty modeling. Through systematic investigations, we have identified several major uncertainty modeling methods that have been applied, including probabilistic methods (Fang et al., 2020), robust optimization (Wang et al., 2019a), interval analysis/probability methods (Shahidinejad et al., 2012; Liu et al., 2021), information gap decision-making theory (Zhao et al., 2017a), and hybrid optimization methods (Guo et al., 2019). Thirdly, there are many IES coupling devices, and the characteristics of the devices, complex network constraints, and multiple uncertain factors lead to highly nonlinear terms in the model. For example, the variable working condition characteristics of the coupling equipment, the dynamic constraints of the heating network, and the maximum-minimum operator in the uncertainty optimization all bring challenges to the optimization operation. In order to facilitate model solving, relaxation and convexification techniques can be used. However, some nonlinear optimizations are still difficult to solve and need to rely on intelligent optimization algorithms such as machine learning (Xi et al., 2020).

Focusing on the above-mentioned difficulties, this paper conducts a systematic and critical review of existing research from three aspects: source-network-load-storage and multienergy market uncertainties, IES uncertainty modeling, and model solution methods. It focuses on the main principles, applications and limitations of various uncertainty modeling methods of IES. And according to the processability, calculation efficiency, convergence speed and optimality and other indicators to select the appropriate solution algorithm. In addition, this article can be used as a basis for future research to solve the uncertainty in IES optimization design.

The paper is organized as follows: Section 2 discusses the structure of a typical IES and introduces a basic optimal operation model. Section 3 discusses the uncertainty of intermittent new energy power generation, the uncertainty of equipment operation status and the system, the uncertainty of load forecasting, the uncertainty of electric vehicle integration, the uncertainty of market rules and energy prices. Various uncertainty modeling methods and solution methods for IES are discussed in Section 4. Sections 5, 6 provide brief discussions and conclusions.

\section{OPTIMAL OPERATION OF INTEGRATED ENERGY SYSTEM}

\subsection{The Structure of Integrated Energy System}

Typical structure of IES as shown in Figure 1, Contains a variety of energy resources such as electricity, gas, heat, cold. Different energy subsystems achieve dynamic balance of energy through various energy conversion equipment. Among them: combined heat-power (CHP) is converted into electric energy and heat by burning natural gas; P2G (Power to Gas) equipment converts electric energy into natural gas, electric refrigerator (EC) can convert electrical energy into cold energy to meet the cooling load needs of users. Electric boilers can convert electrical energy into heat energy, and absorption chillers (AC) can further convert excess heat energy into cold energy. When the energy on both sides of the source load is unbalanced, it can be adjusted by storing or releasing energy through different energy storage devices. It can be seen that mastering the characteristics of each energy subsystem and various coupling devices in IES is the basis for IES's optimized operation.

\subsection{Basic Optimization Operation Model}

According to different modeling ideas and methods, the IES optimized operation model can be divided into two types: general 


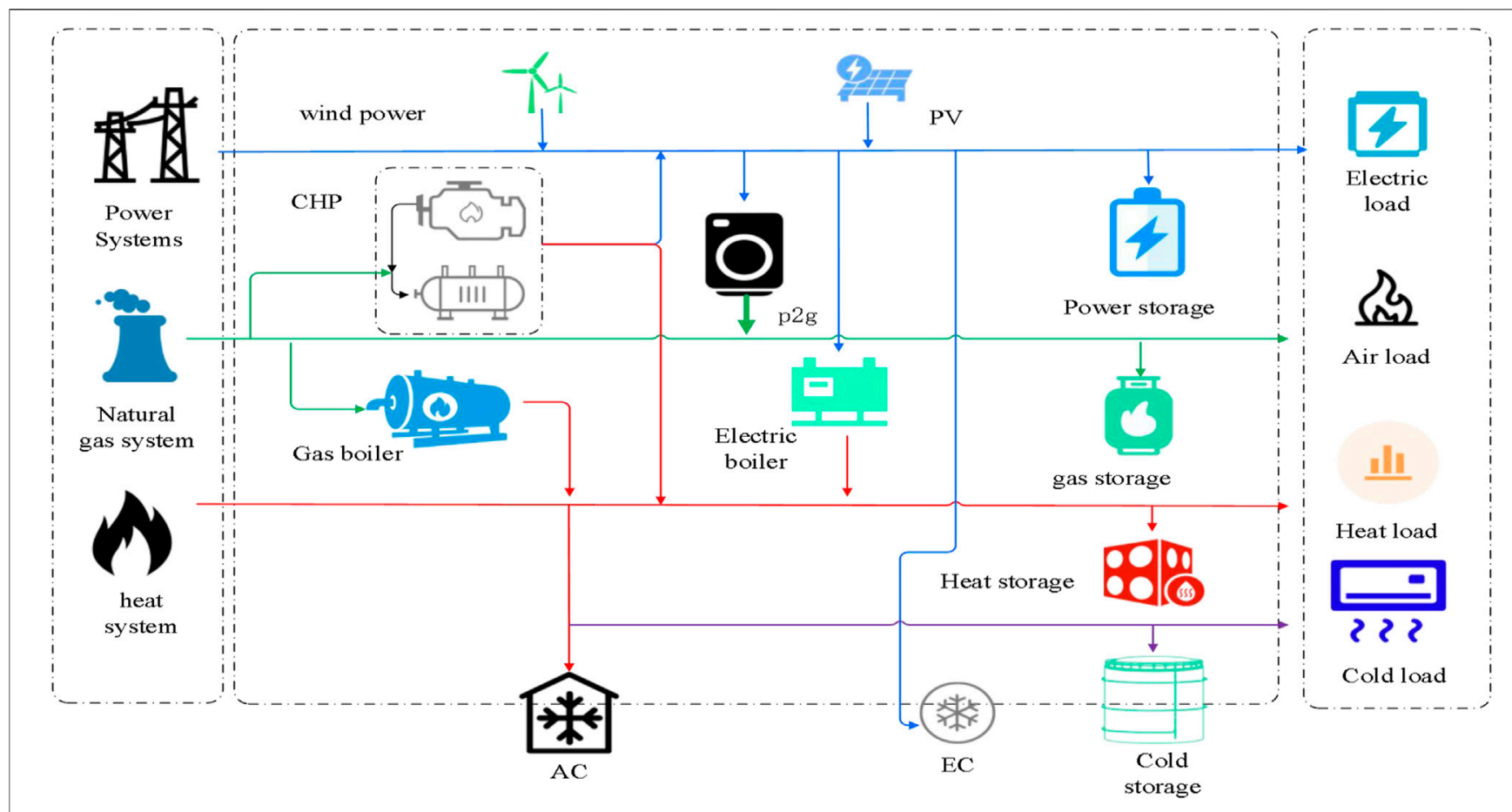

FIGURE 1 | Typical structure of IES.

TABLE 1 | General model for optimal operation of IES.

System

Constraint

Objective function -

Power System

Power balance

Branch trend

Ramp limitation

Reserve capacity

Capacity limitation for each component

Natural Gas Nodal flow balance equation

System

Nodal pressure

Air source output

Escrow characteristic equation

Pipeline flow dynamic model

Heat System

Mass flow balance equation

Loop pressure drop equation

Nodal power balance equation

Temperature drop equation

Propagation delay equation

Pipe heat conduction

Nodal temperature mixing equation

Coupling Element $\mathrm{CHP}$

P2G

$H P$, EB

EC, AC

\section{Description}

Optimal operating cost, maximum social welfare, maximum utilization of RES.

Load demand should be balanced with unit output

Power grid branch power flow should satisfy constraints

The climb of the units is limited by the rate of climb

The upward/downward reserve capacity is coupled with the outputs of units, and it is constrained by the ramping rate

Each component is limited by the maximum and minimum output or power

The flow into the natural gas node is equal to the outflow

The natural gas node should meet the maximum and minimum pressure limits

The output of the air source should meet the maximum and minimum limits

The pipeline injection flow rate is different from the output flow rate, and the difference is stored in the pipeline Described by the partial differential equations of conservation of mass, Newton's second law, and conservation

of energy

Continuity of mass flow at nodes.

The pressure drop in a loop is zero

The thermal dynamic process includes the heat balance in heat sources and heat exchange station

Calculate the temperature at the outlet of the pipe

The delay of temperature changes at both ends of the heating pipe can improve the accuracy of the model The partial differential equations of temperature kinetics and time delay in the thermodynamic process describe the pipeline Temperature distribution

The outlet temperature of the pipeline injected at the junction is mixed at the node, and the temperature out of the node is the mixed temperature

The relationship between heat and power production of $\mathrm{CHP}$ units

Including two steps of water electrolysis and hydrogen methanation

The relationship between heat production and power consumption for HPs/EBs

The relationship between the cold production and power consumption for ECs/ACs 


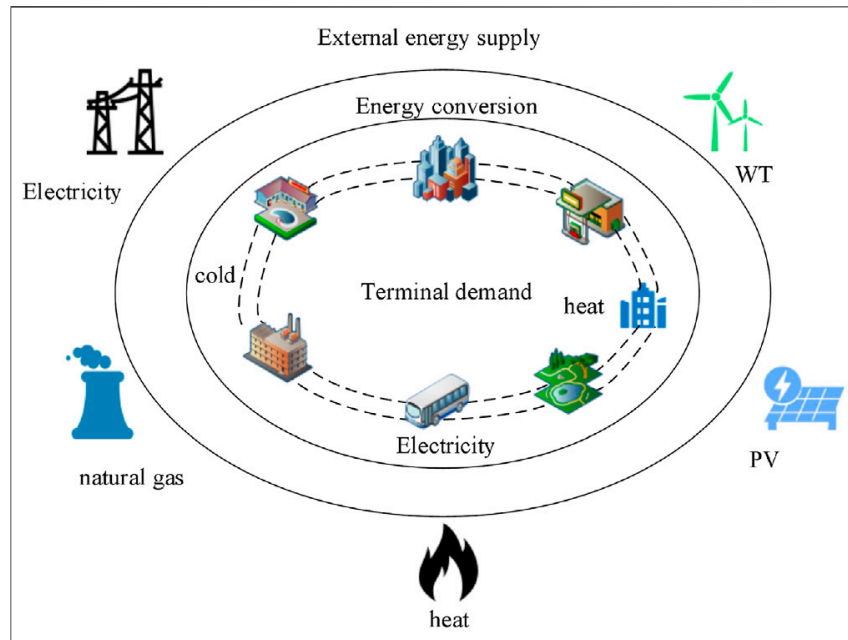

FIGURE 2 | The structure of the energy hub.

model and unified model. The general model is to model each energy subsystem and coupling components separately. Unified modeling uses theories of energy hubs or circuits to uniformly express the process of energy transmission, conversion, and storage.

\subsubsection{General Model}

The general model of IES optimization operation is composed of objective function and constraint conditions, as shown in Table 1. The objective function is usually the lowest system operating cost, the highest renewable energy consumption rate, and the lowest carbon emissions. According to the number of optimization goals, it can be divided into single-objective optimization and multi-objective optimization. Among them, when considering multi-objective optimization, dispatchers need to weigh different optimization objectives to make optimal decisions. The constraint is the feasible region of each device and the entire system. It should be noted that the formula in Table $\mathbf{1}$ is only a basic form, which can be adjusted according to specific research scenarios and system operating modes.

\subsubsection{Unified Model}

At present, the unified model includes the energy hub model and the unified energy path model (Wang et al., 2019b). The theory of energy hubs was put forward by Goran Anderson and others of ETH Zurich. The energy concentrator summarizes the energy form of IES on both sides of energy supply and energy demand, and describes the energy coupling characteristics through the elements in the coupling matrix, and realizes the functions of coordinated transmission, conversion, storage, and distribution of multiple energy sources. The structure of the energy hub is shown in Figure 2.

The unified energy path theory (Chen et al., 2020b) was proposed by the team of Tsinghua University. Based on circuit theory, a unified energy circuit including power network, gas circuit, water circuit, and heat circuit is derived. The energy network is represented as an energy path diagram composed of a number of branches containing energy path elements such as resistance, capacitance, and sense connected according to a certain topological relationship. By analyzing the branch characteristics and topology constraints in the energy path diagram, the network matrix and network equations of each energy network can be derived, which reduces the amount of calculation. It provides a unified theory and efficient method for the modeling, analysis and optimization of multi-energy networks, and has broad application prospects in the planning and operation of IES.

\section{UNCERTAINTY FACTORS FOR OPTIMIZATION OF IES}

The uncertain factors in the optimal operation of the integrated energy system can be roughly divided into the uncertainty of intermittent new energy power generation, the uncertainty of the equipment operating state and the system, the uncertainty of load forecasting, the uncertainty of electric vehicle grid connection, and the uncertainty of energy prices and market rules correspond to the uncertainties of source-network-load-storage and multienergy trading markets, respectively.

\subsection{Uncertainty on the Source Side}

The uncertainty on the source side mainly considers the volatility of renewable energy output and the forecast error of renewable energy output. On the one hand, the output of renewable energy is easily affected by environmental factors, and the randomness of weather factors will affect the power of wind turbines. Similar to wind speed, the total horizontal solar irradiance, temperature, humidity, cloud cover, air pressure, etc. have a great influence on the photovoltaic output power (Dai et al., 2011). It is generally believed that the wind speed obeys the Weibull distribution, and the light intensity obeys the beta distribution. The strong randomness and volatility of renewable energy generation power will inevitably affect the stable operation and optimal control of the distribution system (Tuan et al., 2020; Doan et al., 2021). In view of the smoothing effect of the energy storage system on the grid-connected power of renewable energy generation, through the coordinated dispatch of "source-gridload-storage", the distribution system can be actively controlled and managed to improve the consumption of renewable energy and ensure safety economic operation. On the other hand, in the intra-day optimization scheduling process, the data of the previous day's renewable energy output is usually used as a benchmark. There is usually a certain error between the actual value and the predicted value of renewable energy output. The day-ahead forecast error of renewable energy output is as high as $25-40 \%$ of installed capacity. High-precision forecasting is an effective means to alleviate the negative impact of renewable energy grid connection on the system (Zhang et al., 2016). According to existing research, the forecasting models of renewable energy output can be divided into physical models and statistical models. Commonly used statistical forecasting methods include time series method, artificial neural network method and support vector machine (Liu et al., 2017a). 
TABLE 2 | The equipment with obvious variable operating conditions in IES.

\begin{tabular}{|c|c|c|c|}
\hline Equipment & \multicolumn{2}{|l|}{ Formula } & Description \\
\hline- & \multicolumn{2}{|l|}{$\bar{\eta}=f(\bar{N})$} & The conversion efficiency $\bar{\eta}$ varies with the change in the actual load rate $\bar{N}$ \\
\hline $\mathrm{CHP}$ & \multicolumn{2}{|c|}{$\bar{\eta}=3.18 \bar{N}-4.69 \bar{N}^{2}+3.69 \bar{N}^{3}-1.18 \bar{N}^{4}$} & $\begin{array}{l}\text { The performance of the CHP unit is associated with a variety of factors such as operating temperature, } \\
\text { humidity, pumping coefficient and load rate. Assuming that other parameters are constant, the efficiency } \\
\text { values of the CHP unit gradually decrease as the load rate decreases }\end{array}$ \\
\hline GB/WHB & $\left\{\begin{array}{l}0 \\
0.82+0.19(\bar{N}-0.05)\end{array}\right.$ & $\begin{array}{l}\bar{N}<0.05 \\
0.05 \leq \bar{N} \leq 1\end{array}$ & $\begin{array}{l}\text { The conversion efficiency of the GB, WHB in the variable condition can be approximated by segmentation } \\
\text { linearization }\end{array}$ \\
\hline $\mathrm{AC}$ & $\left\{\begin{array}{l}1 \\
0.5+0.83(\bar{N}-0.05)\end{array}\right.$ & $\begin{array}{l}0.65 \leq \bar{N}<1.0 \\
0.05 \leq \bar{N}<0.65\end{array}$ & $\begin{array}{l}\text { There are two types of coolants commonly used by AC, and lithium bromide is widely used in Asia and the } \\
\text { United States. Europe should have more water/ammonia }\end{array}$ \\
\hline
\end{tabular}

\subsection{Uncertainty on the Grid Side 3.2.1 Equipment Operating Status}

At present, the uncertainty research on the equipment operating status includes two types: equipment variable operating conditions and equipment failure. The variable-condition characteristics of the equipment means that the efficiency of the energy conversion equipment is not constant, it is related to power, load rate, environmental factors, etc. (Wang et al., 2018). At present, certain researches have been carried out on the characteristics of equipment under variable conditions. Chen et al. (2020c) established an RIES optimal scheduling model based on dynamic $\mathrm{EH}$ considering the characteristics of equipment under variable conditions, which improves the accuracy of the equipment model and reduces the cost prediction error of the scheduling scheme. Wei et al. (2015), Deng et al. (2017) proposes an economic optimization model that considers the characteristics of the equipment under variable conditions for small internal combustion generator sets, CHP, and energy production equipment. Considering the characteristics of equipment under variable conditions will make the model have nonlinear constraints. Using polynomial fitting for linearization or piecewise linearization can preserve the linear coupling relationship between the input and output of the device, but there are still large errors (Huang et al., 2020). At present, the optimized operation of IES takes less consideration of the characteristics of equipment under different conditions. Existing research mainly focuses on the impact of a single factor on equipment efficiency. In the future, more influencing factors should be considered to further refine the equipment efficiency characteristic model. The equipment with obvious variable operating conditions in IES is shown in Table 2.

Equipment failure is another important uncertainty factor in equipment modeling. The failure of a certain device in the IES may cause a subsystem or even the entire system to fail. At present, the fault model of equipment in IES is generally built as a two-state or multi-state model (Zhong et al., 2013; Ding et al., 2014a; Ding et al., 2014b), and its normal operation time and failure duration are simulated by exponential distribution. Ding et al. (2014a) pointed out that the random failure or aging of the traditional generator set will cause the complete or partial failure of the generator set, which will affect the output of the generator set. Ding et al. (2014b) uses a universal generating function to represent a multi-state model of wind speed, and considers the failure rate of wind turbines, and establishes a wind farm output Markov process model that comprehensively considers wind speed and wind turbine failures. Zhong et al. (2013) analyzes the physical structure of the grid-connected energy storage system, and based on the state space method, carries on the reliability modeling of the battery energy storage system. When a fault occurs in the IES, the mutual influence of the coupled energy systems will expand the scope of the fault and increase the difficulty of handling the fault. Therefore, it is necessary to predict equipment failures. Dawn An et al. divide the failure prediction methods into three categories: mechanism-based methods, data-driven methods, and methods that combine mechanism and data-driven. But most data-driven methods lack the support of mechanism. Therefore, it is necessary to combine the above two methods to improve the performance of fault prediction.

\subsubsection{System Uncertainty}

In addition to considering the uncertainty of energy demand and supply in each energy subsystem, the inherent uncertainty of natural gas and heating pipeline parameters and outdoor temperature cannot be ignored. First of all, the parameters of the pipeline are not constant values and are affected by the operating status of the system. As there is not enough monitoring device installed, the deviation of the actual value of the pipeline parameter from its normal value is difficult to be observed. Secondly, the cooling and heating requirements and energy comfort of end users are affected by building parameters and outdoor temperature. Therefore, the thermal inertia of the building and the prediction error of outdoor temperature should be considered when modeling the uncertainty of cold and heat demand (Li et al., 2020b; Lu et al., 2020; Li et al., 2021).The uncertain factors contained in each energy subsystem will affect the actual operation of IES through the coupling of multiple energy flows and multiple time scales. In addition, IES is a typical application of in-depth integration of cyber-physical systems. Its uncertainty is not only related to the energy physical system itself, but also closely connected to the information system. The uncertain factors of the information system, such as measurement abnormalities, information transmission errors, random failures of the information system, and human information attacks, will directly affect the physical system. Lei et al. (2014) studied the impact of information system components and their failure modes on physical systems. Lei and Singh (2017) uses non-sequential Monte Carlo simulation to sample the state space of devices with different dependencies, and analyzes the reliability of the corresponding cyber-physical system. 


\subsection{Uncertainty on the Load Side 3.3.1 Analysis of Influencing Factors}

IES comprehensively covers electricity, gas, heat (cold) and other energy forms, many influencing factors, such as: building indoor conditions, building parameters, climate, social economy, etc., will increase the uncertainty of the load.

1) Building indoor conditions: mainly including energy-using equipment, users' own energy-using behavior, indoor environmental quality requirements (temperature, humidity, air quality), etc., in which indoor environmental quality requirements affect the load most influential.

2) Building parameters: Building materials affect the heating/ cooling load of a building, and factors such as building location, size, height, shape, and window-to-wall ratio will affect building lighting, solar radiation intensity and ventilation conditions.

3) Climate: Mainly includes outdoor temperature, humidity, solar radiation, extreme weather (fog, dew, frost, etc.). Climatic factors will directly affect the energy demand of users (Lu et al., 2019; Wu et al., 2021).

4) Socio-economic factors: mainly including education level, energy price, economic level, etc., which will affect the user's energy consumption habits, equipment configuration and other factors, thereby affecting the end user's load.

\subsubsection{Load Forecasting}

Compared with renewable energy, the uncertainty of output is mainly related to its own characteristics. The uncertainty of load is regular, so the accuracy of load forecasting is often much higher than that of renewable energy (Mamun et al., 2020). At present, IES load forecasting methods can be divided into macro-type forecasting methods, micro-type forecasting methods and artificial intelligence methods. According to the specific object, suitable forecasting method or combination forecasting method can be selected. Macro forecasting methods use statistical methods to find the relationship between energy consumption and economic, natural environment, population and other factors from a macro perspective. The classical forecasting methods generally used include time series method, regression analysis method, elasticity coefficient method, load density method, and trend extrapolation method, etc. (Wang et al., 2011; Si et al., 2020). The micro forecasting method uses a non-aggregated model to analyze the energy consumption of each user and add up to get the total load demand in the area. Compared with the macro-type forecasting method, the results reflect energy consumption characteristics and the forecast results are more accurate, but the preliminary data collection process is complicated. In recent years, artificial intelligence technologies represented by machine learning and deep learning have been widely used in the field of load forecasting, making full use of the measurement data in smart meters to study the energy demand and behavior of different types of users and groups, based on massive energy data establishes self-learning models for different types of users (Kong et al., 2018). It is not restricted by load components and characteristics, and has certain advantages in describing complex dynamic behavior characteristics. It is foreseeable that the theory of artificial intelligence based on big data will be an effective way to solve IES multiple load joint forecasting in the future.

\subsection{Uncertainty on the Energy Storage Side}

Energy storage systems are mainly divided into three categories: fixed energy storage, mobile energy storage and virtual energy storage. Most of the existing studies use energy storage as a flexible resource to participate in the optimal scheduling of IES. The installation of different types of energy storage equipment can change the distribution of load in the space and time dimensions, and minimize the difference in the distribution of electricity, heat, and gas load as much as possible (Fang et al., 2018). However, the uncertainty of energy storage itself is rarely considered.

Mobile energy storage has the characteristics of good mobility and easy installation, and can be configured in different spaces and time periods. As a typical representative of mobile energy storage, the actual charging load of electric vehicles fluctuates randomly due to the influence of vehicle operation, traffic, environment and other factors, showing strong uncertainty. The commonly used modeling methods for uncertainty analysis of electric vehicles include Monte Carlo simulation, fuzzy methods and a mixture of the two. Rassaei et al. (2018) uses fuzzy technology to divide the important factors in EV load modeling into several groups to calculate EV load demand and charging time. The hybrid fuzzy-MCS method can consider the spatial and temporal uncertainty of EV at the same time.

Virtual energy storage is to achieve load peak reduction and valley filling by integrating controllable resources on the user demand side. More and more users are participating in market supervision activities. However, when users participate in demand response, they will be affected by market prices, policy incentives, energy usage habits, communication delays, environmental conditions and other factors (Rassaei et al., 2018). Therefore, the uncertainty is stronger and it is difficult to accurately predict. In addition, with the popularization of advanced measurement devices, more and more scattered users have the opportunity to participate in power grid dispatch, especially some small and medium-sized users, which greatly aggravates the uncertainty of demand response.

\subsection{Uncertainty on the Multi-Energy Trading Market}

\subsubsection{Trading Methods}

Market transactions are divided into three types: bilateral transactions, centralized transactions, and peer-to-peer transactions. Bilateral transaction means that both parties to the transaction sign a contract through negotiation to ensure that a certain amount of a certain subject matter is bought and sold within an agreed time according to a pre-agreed price and method (Farzin et al., 2019). The scale of the transaction is related to market rules and transaction costs. Due to the influence of various uncertain factors such as IES load, equipment failure, network transmission capacity, etc., there is a certain error between the transaction volume specified in the bilateral 
contract and the actual demand volume. Therefore, it is necessary to set up centralized transactions. Centralized trading means that market participants make quotations to the market organizers according to the quotation rules, and the market organizers uniformly clear the market in accordance with the bidding rules (Farzin et al., 2019), determine the bid amount and bid price of each market participant. With the liberalization of the trading market, a peer-to-peer distributed energy trading method has emerged. For example: Distributed renewable energy operators can directly sign contracts with users or energy storage operators to reduce users' energy costs and increase the revenue of energy storage operators. The liberalization of transactions has made the energy flow of regionally distributed markets more complicated, changing from a single direction to an uncertain direction. At the same time, the development of ancillary services, financial derivatives, carbon trading, and green certificate markets will further enrich the trading varieties of diversified entities. The increase in trading methods and trading entities makes the operation of IES full of more uncertainties.

\subsubsection{Market Operation Mechanism}

The operating mechanism ensures the optimal allocation of resources in the multi-energy market, and consists of mechanisms such as price, supply and demand, competition, settlement, and incentives. In the multi-energy market, the price mechanism is full of uncertainty. The transaction price is affected by the supply and demand of multiple energy sources, the degree of network congestion, and is also related to the different development stages of the transaction model. In addition, in the multi-energy trading market, the trading cycles of different energy sources are different on the time scale, which is prone to information delay. At the same time, users have different sensitivity to different energy prices, the participation response is random and lagging. Chen et al. (2018) established a consumer decision model based on the utility function of constant elasticity of substitution (CES) according to the impact of consumers' decision-making behavior on energy prices. It also analyzes the game relationship among consumers, heat market and electricity market. Adopting end-to-end energy trading in (Xu et al., 2018) can realize the equal and free trading of multiple energy sources. The introduction of the carbon trading market makes the IES system not only participate in the competition in the energy market, but also in the competition in the carbon trading market. At the same time, carbon market prices and energy market prices will affect each other, increasing the uncertainty of market operation mechanisms. In the carbon trading market, the competitive advantage of renewable energy power generation has gradually increased, and the competitive advantage of traditional thermal power units has declined significantly, which has changed the competitive landscape of the energy market. Big data analysis, data mining and other technologies can improve the core competitiveness of market players. Hannan et al. (2018) uses artificial intelligence methods to analyze multi-energy trading equilibrium and bidding strategies through sample learning, breaking through the barriers of a single energy market.

\section{UNCERTAINTY MODELING METHOD OF IES}

The current methods for optimal operation of integrated energy systems that consider uncertain factors are divided into Stochastic optimization, robust optimization, interval optimization, possibility method, information gap decision theory (IGDT), and hybrid optimization method. The optimization objectives can be divided into: Economy, environmental protection, reliability, flexibility or their combination.

\subsection{Stochastic Optimization}

\subsubsection{Principle}

Stochastic optimization uses the probability density functions (PDFs) of random variables to characterize the uncertainty of the system, and uses different probability strategies to deal with it, such as: scene method, Monte Carlo simulation, point estimation method, chance constrained programming, etc. Usually, the probability distribution of random variables needs to be assumed first, but the assumed probability distribution may not be accurate enough to describe the uncertainty, and a trade-off between calculation accuracy and calculation efficiency is required.

The scenario method is a common strategy for dealing with uncertain parameters based on scenario analysis. The current scene generation methods mainly include Monte Carlo sampling, Latin hypercube sampling and probability sampling. The scale of the basic scene obtained by the scene generation method is large, and a reasonable reduction is required to screen out typical scenes that meet the statistical characteristics of uncertain variables. Scene reduction methods mainly include backward/forward reduction methods, scene tree division and cluster division. The scenario method usually divides uncertain parameters into countable limited scenarios with specific probabilities. That is, a series of scenes are generated through the PDF of each uncertain parameter, and the expected value of the output variable $y$ is obtained. The calculation is as follows:

$$
E(y)=\sum_{s} \pi_{s} \times f\left(x_{s}\right)
$$

Where $\sum \pi_{s}=1, \pi$ is the probability of scene S. $f\left(x_{s}\right)$ is the probability density function under scene $S$.

MCS is used for highly nonlinear, complex or systems with many uncertain variables. Three different types of MCS techniques are used for uncertainty analysis in practical applications: Sequential Monte Carlo, Non-sequential Monte Carlo simulation and Pseudo-sequential Monte Carlo simulation (Aien et al., 2016). MCS is an iterative method, the calculation process is shown in Figure 3.

The point estimation method is based on the moment of uncertain input parameters, and the output variable is described as a Gaussian probability density function. The point estimation method concentrates the statistical information provided by the first few central moments of random variables on the concentrated point of each variable. The point estimation method is divided into $\mathrm{km}$ scheme and $\mathrm{km}+1$ scheme $(\mathrm{K}$ is a 
parameter). The $\mathrm{km}+1$ scheme is more accurate than the $\mathrm{km}$ scheme because it counts variable peaks. Chance-constrained programming (CCP) allows a constraint to be violated with a predetermined small probability. Taking into account the uncertainties of load and photovoltaic output, as well as the correlation between these uncertainties, in some extreme cases, violation of inequality constraints is allowed. Therefore, control measures for extreme situations that rarely occur can be avoided. The general model of CCP is as follows (Wu et al., 2020):

$$
\begin{cases}\min \sum_{j=1}^{m} P_{j} \sum_{i=1}^{n}\left(U_{i j} d_{i}^{+}+V_{i j} d_{i}^{-}\right) \\ \text {s.t. } \quad P_{r}\left\{f_{i}(x, \eta)-b_{i} \leq d_{i}^{+}\right\} \geq \delta_{i}^{+} \\ & P_{r}\left\{b_{i}-f_{i}(x, \eta) \leq d_{i}^{-}\right\} \geq \delta_{i}^{-} \\ & d_{i}^{+}, d_{i}^{-} \geq 0\end{cases}
$$

Where $f_{i}$ is the objective function; $\mathrm{m}$ is the number of priorities; $\mathrm{n}$ is the number of target constraints; $p_{j}$ is the target priority factor, $b_{i}$ is the $i$-th target value; $u_{i j}, v_{i j}$ are respectively the positive deviation weighting factor and the negative deviation weighting factor of the $\mathrm{i}$-th target of the $j$-th priority. $d_{i}^{+}, d_{i}^{-}$are respectively the optimistic positive deviation and the optimistic negative deviation of the $i$-th target from the target value.

\subsubsection{Application}

Stochastic optimization was originally proposed by Danzig (1955). We summarized the application of stochastic optimization in IES. The multi-stage stochastic optimization model of the electricity-gas integrated energy system considering the uncertainty of wind power output is proposed in Qadrdan et al. (2014), it is transformed into a deterministic optimization model through scenario generation and reduction technology for solution. Liu et al. (2014) analyzes the uncertainty of solar energy and heat load in the operation of building energy system based on the method of multi-stage scenario tree. Yao and Wang (2020) considers the extreme conditions of the wind and solar scene set, and establishes a two-level multi-scenario collaborative optimization configuration model for the IES. The scenario analysis method is complex and time-consuming, it is not suitable for large-scale systems. The MCS method is intuitive and relatively easy to implement. The Chen et al. (2017) uses the Monte Carlo method to analyze the probabilistic energy flow of IES. Oh et al. (2020) considers the relative changes in energy demand and wind power output, generates random samples for uncertain inputs through MCS, and uses a multilinear method to solve them. As the degree of freedom of the solution space increases, the number of simulations required for MCS also increases, requiring a considerable amount of calculation. Compared with MCS, the point estimation calculation is more efficient, easy to implement and has higher accuracy. The most widely used point estimation method is the three-point estimation method. Sun et al. (2017a) constructs an IES day-ahead optimal scheduling probability model, and uses the second-order cone programming (SOCP) and point estimation method to solve it. Zhao et al. (2017b) uses a three-point estimation method to model the uncertainty of the gas supply capacity, assign corresponding probabilities according to the actual situation of the system. Since there is a certain correlation between random variables in IES, the point estimation method is usually used in conjunction with the correlation processing methods such as Nataf transform and orthogonal transform. CCP is actually a stochastic optimization method. Liu et al. (2017b) uses CCP to describe the uncertainty in the power system, so that the scheduling results can meet the actual operation requirements under a certain level of confidence. The stochastic optimization problem with chance constraints is transformed and solved by sampling average estimation, scene approximation and other methods. When the uncertain parameters obey the normal distribution, it can be transformed into a deterministic second-order cone optimization problem (Fang et al., 2020).

\subsection{Robust Optimization}

\subsubsection{Principle}

Robust optimization describes the fluctuation of uncertain parameters through uncertain sets. As long as the values of uncertain parameters are within the range of uncertain sets, the feasibility of the solution can be guaranteed.The selection of the "uncertain set" is the key to robust optimization to deal with the uncertainty problem. At present, the uncertain set is often described in the form of box, polyhedron, ellipsoid, cardinality, etc. With the development of robust optimization technology, it can be divided into engineering game model, twostage robust optimization model, and distributed robust optimization model according to different modeling ideas.

The engineering game model of robust optimization refers to the uncertainty factor trying to make the system operation index worse, while the system decision maker tries to give a strategy to keep the operation index optimization under all possible conditions (Mei et al., 2013). The commonly used engineering models for robust optimization is:

$$
\begin{aligned}
& \min \max J(u, w) \\
& \text { s.t. }\left\{\begin{array}{l}
G(x, u, w) \leq 0 \\
u \in U \\
w \in W
\end{array}\right.
\end{aligned}
$$

Where $J(u, w)$ is the objective function; $G(x, u, w)$ is a constraint condition, $\mathrm{x}$ is a system state variable, $\mathrm{U}$ and $\mathrm{W}$ are decision variables and random variables, respectively.

The engineering robust optimization method has strong pertinence and practicability for engineering game problems, but the decisions made are too conservative. The two-stage robust optimization method overcomes the shortcomings of the engineering robust optimization method that is too conservative. The main idea is to divide decision variables into adjustable variables and non-adjustable variables for staged decision-making. Some of the decision variables make corresponding decisions before the uncertainty is realized, and the other part of the decision variables can be adjusted according to the uncertainty. It is mainly based on affine adjustable robust optimization and two-stage adaptive robust optimization. Affine adjustable robust optimization uses an affine function to establish an affine relationship between an adjustable variable and the 
uncertain parameter it depends on. The two-stage adaptive robust optimization model is adaptive to uncertainty. Compared with the affine adjustable robust optimization model, the structure is more complicated, but it has greater flexibility in adjusting the day-ahead operating point in the real-time exploration phase.

The two-stage robust optimization model is:

$$
\begin{aligned}
& \min \quad C^{T} y+\max _{u \in U} \min _{x \in F(y, u)} b^{T} x \\
& \text { s.t. } \quad A y \geq d, y \in\{0,1\} \\
& F(y, u)=\{E x \geq h-F u-G y: \lambda\}
\end{aligned}
$$

Where $y$ is the decision variable in the first stage, optimized according to the prediction information of the uncertain variable, robust to any uncertain set scenario; $\mathrm{u}$ is the uncertain set, $\mathrm{x}$ is the decision variable in the second stage, $\lambda$ is the dual variable of the corresponding constraint.

Aiming at the relatively conservative shortcomings of robust optimization methods, a distributed robust optimization model is proposed. The distributed robust optimization method establishes an ambiguity set of probability distribution based on part of the information of the uncertain variable, and makes an optimal decision for the worst probability distribution of the fuzzy set. The construction of the fuzzy set of probability distribution is the basis of the solution of the distributed robust optimization model. It mainly uses fuzzy sets based on statistical moments and distance-based probability distributions. The general mathematical form of distributed robust optimization is:

$$
\min _{x \in X} \sup _{p \in \Omega}\left\{E_{p}[f(x, z)]\right\}
$$

Where: $\mathrm{x}$ is a decision variable, $\mathrm{z}$ is a parameter, $\Omega$ is a fuzzy set of parameter distribution constructed based on historical information. $E_{p}$ is the expected value of the distribution of uncertain variables.

\subsubsection{Application}

The robust optimization method was proposed by Soyster (1973). We summarized the application of robust optimization in IES. In (Zugno et al., 2016), considering the uncertainty of electricity price and heat load, an affine adjustable robust optimization IEHS model was developed. For the convenience of calculation, it is assumed that the unit adjustment is a linear function of uncertain parameters. Zhou et al. (2020) established a two-stage robust IEHS scheduling model, which imposes fuzzy constraints on the uncertainty of the heat load of the heating network, the ambient temperature and the heat dissipation coefficient of the heating pipe, and is solved by the C and CG algorithm. Although the robust constraint cannot fully capture the flexibility of the region to deal with the combination of uncertain scenarios, it can ensure that the system can cope with the worst case. In the actual operation of IES, each energy subsystem often belongs to different operators, and there are industry and information barriers, which limit the two-stage robust optimization model of the unified dispatch mode. Later, researchers proposed a variety of methods such as distributed robust optimization and data-driven distributed robust optimization. Distributed robust optimization does not need to set the probability distribution type, and makes decisions based on the worst probability distribution in fuzzy sets. Compared with random optimization, it is more robust. He et al. (2019), Zhang et al. (2019) establishes a distributed robust optimization model, constructs a fuzzy set based on wind power error sample data, and solves it through linear decision-making, which has a high computational time cost. Zhao et al. (2019) establishes a twostage distributed robust optimization model for the energy hub. A new multi-modal fuzzy set is proposed to deal with the prediction error of photovoltaic power generation, and it is compared with the widely used normal fuzzy set and unimodal fuzzy set. Datadriven distributed robust optimization constructs fuzzy sets by mining historical data, which further improves the economics of the scheme (Xu and Chen, 2021).

\subsection{Interval Optimization/Possibility Method 4.3.1 Principle}

Interval optimization is similar to robust optimization, only requires the upper and lower bounds of the uncertainty without the need for its accurate probability distribution. It uses interval numbers to describe uncertainty, which is suitable for situations where there are a large number of unknown factors and statistical data is difficult to obtain.

The general model used in interval optimization is as follows:

$$
\left\{\begin{array}{l}
\min f(x, u) \\
\text { s.t.g } g_{\xi}(x, u) \geq b_{\xi}^{I}=\left[b_{\xi}^{-}, b_{\xi}^{+}\right] \\
U \in U^{J}=\left[U^{-}, U^{+}\right] \quad \xi=1,2, \ldots, S \\
U_{\delta} \in U_{\sigma}^{J}=\left[U_{\sigma}^{-}, U_{\sigma}^{+}\right] \quad \delta=1,2, \ldots, q
\end{array}\right.
$$

Where $X$ is the u-dimensional decision variable matrix; $U$ is the $q$ dimensional uncertain variable matrix; $g_{\xi}(x, u)$ is the $\xi$-th uncertainty constraint; $S$ is the number of uncertain constraints; $b_{\xi}^{I}$ is the interval of the constraint equation; $U^{J}$ is the interval matrix of uncertain variables. $U_{\delta}$ represents the $\delta$-th uncertain variable, which is an element of $U^{J}$.

The membership degree of the uncertain variable input by the possibility method is represented by a suitable fuzzy membership function (MF). Suppose the original optimization problem can be expressed as:

$$
\left\{\begin{array}{l}
\min f(x) \\
\text { s.t. } g(x, \phi) \leq 0
\end{array}\right.
$$

Where $\mathrm{x}$ and $\varphi$ denote decision variables and fuzzy variables, respectively.

When the shape of the membership function is not considered, the main problem is that the MF of the input variable is known, how to determine the MF of the output variable? Usually the $\alpha$-cut method and defuzzification strategy are used to solve the problem. The $\alpha$-cut method is the probability distribution of the known uncertain input variable $\mathrm{X}$, and the possibility distribution of $\mathrm{Y}$ can be obtained by the $a$-cut method. The constraint condition contains fuzzy variables so that the optimization problem cannot obtain deterministic results, and the defuzzification strategy can be used to defuzzify the output variables. The centroid method is a commonly used defuzzification strategy. 


\subsubsection{Application}

The concept of probability method modeling was first proposed by Zade (Zadeh, 1999). Considering the uncertainty of wind power, photovoltaic power generation and light field thermal power, the IES fuzzy constraint planning model (Dong et al., 2020) is established. By introducing the confidence level $\alpha$, the problem becomes a form of chance constraint expression, which is then transformed into solving a deterministic optimization problem. The uncertainty model of the energy conversion efficiency of natural gas network pipeline parameters and P2G equipment is established using the ladder fuzzy membership function (Sun et al., 2017b). Using fuzzy technology, important factors in EV load modeling can be divided into several groups to calculate EV load demand and charging time (Shahidinejad et al., 2012). The quality of the results obtained by the possibility method depends to a large extent on the selection of fuzzy membership functions. Due to the lack of criteria for selecting membership functions, the results obtained are highly subjective. Interval optimization can obtain optimistic and pessimistic solutions that meet the requirements of system operation. The calculation is relatively simple and can highlight the impact of uncertain parameters on the system. The fuzzy predictive range model is used as a predictive model, and a robust energy management system (REMS) is established. The model considers the nonlinear dynamic behavior and the uncertainty of renewable energy (Valencia et al., 2016). Considering demand response and wind power uncertainty, a coordination operation strategy based on interval optimized integrated energy systems is proposed (Su et al., 2017). Liu et al. (2021) From the perspective of source load synergies, consider the uncertainty of supply and demand, proposing a new multi-target interval optimization framework for energy hub planning issues.

\subsection{Information Gap Decision Theory 4.4.1 Principle}

IGDT is a method to deal with uncertainty in the absence of available historical information and unable to use PDF or MF modeling. When uncertainty occurs, the operator needs to adopt a risk aversion strategy or a risk seeking strategy to deal with the situation caused by the uncertainty. Risk aversion strategy refers to making robust decisions about the errors that may be caused by the prediction of uncertain input parameters. In the case of the largest level of uncertainty, the objective function of the system should avoid exceeding the set value. Expressed with equations as:

$$
\hat{\alpha}\left(f_{r}\right)=\max _{\alpha}\left\{\alpha: \max (f(x, \gamma)) \leq f_{r}\right\}
$$

Where $f_{r}$ is a predetermined cost that the system's maximum total cost cannot exceed. Robust Function $\hat{\alpha}\left(f_{r}\right)$ is understood to exceed the allowable deviation of the set value.

The risk seeking strategy is that the minimum cost of the system cannot exceed the specified cost when the predicted uncertain parameters are slightly error (minimum uncertain radius).

$$
\hat{\beta}\left(f_{0}\right)=\min _{\beta}\left\{\alpha: \min (f(x, \gamma)) \leq f_{0}\right\}
$$

Where $f_{0}$ is the specified cost that the minimum total cost of the system cannot exceed. The chance function $\hat{\beta}\left(f_{0}\right)$ is expressed as the minimum level of uncertainty acceptable to achieve a profit target as large as $f_{0}$.

\subsubsection{Application}

IDGT can be used to deal with issues such as market price, power generation and load uncertainty in IES optimized operation. Vahabzad et al. (2020) applies the IGDT method to multi-energy systems to manage load uncertainty risks. Zhao et al. (2017a) proposed a scheduling method for EV aggregators, using IGDT to deal with the uncertainty of electricity market prices. Cao et al. (2018) proposed a chance constrained-IGDT model for multiperiod microgrid expansion planning considering both random and non-random uncertainties. Dolatabadi et al. (2019) proposes an energy hub system scheduling strategy based on hybrid stochasticIGDT optimization. Energy hub operators choose strategies to avoid and seek risks under price uncertainty.

\subsection{Hybrid Optimization Method 4.5.1 Principle}

The previous method is mainly used to solve a single uncertain variable. There are many uncertain factors in the optimal operation of the IES. When considering multiple uncertain factors, a combination of the above methods is required. Among them: possibility-stochastic optimization method, interval-stochastic optimization method, fuzzy-chance constrained programming, etc. are more applications.

Probability-Stochastic Optimization: Combine the probability method and the probability method through the following two main loops.

Outer loop: Probabilistic method, which analyzes the uncertainty of probabilistic variables.

Inner loop: possibility method, which evaluates the uncertainty of the possibility variable.

The general form of the interval-stochastic optimization model is as follows:

$$
\left\{\begin{array}{l}
\min [f]=[C][X] \\
\text { s.t.P } \\
\{[D][X] \leq[G]+\Delta p\} \geq \beta \\
{[U][X] \leq[Q]} \\
{[X] \geq 0} \\
\delta_{q} \in\{0,1\}
\end{array}\right.
$$

Where $[f]$ represents the operating cost of the system; $[C],[D],[U]$ represents the coefficient matrix; $[X]$ represents the decision variable, $[G]$ and $[Q]$ represent uncertain parameter interval, $\beta$ represents the given confidence level, and $\beta \in[0,1], \delta_{q}$ represents the binary variable in the constraint condition.

Fuzzy-chance constrained programming refers to an optimization method in which when fuzzy variables appear in the optimization problem, the decision result makes the possibility of the constraint condition not less than a given confidence level.

$$
\left\{\begin{array}{l}
\min f(x) \\
\text { s.t. } C_{r}\{g(x, \psi) \leq 0\} \geq \alpha
\end{array}\right.
$$




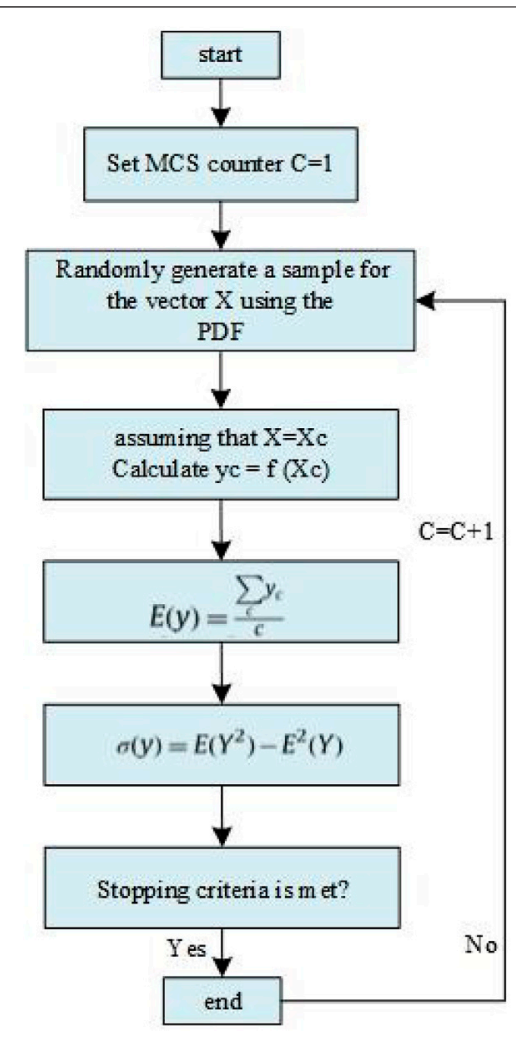

FIGURE 3 | The calculation process of MCS.

Where $\mathrm{x}, \varphi$ represents the decision variable and the fuzzy variable respectively; $f(x), g(x, \varphi)$ represents the optimization objective function and the constraint condition containing the fuzzy variable respectively. $C_{r}\{g(x, \psi) \leq 0\} \geq \alpha$ represents the credibility of $g(x, \psi) \leq 0$.

\subsubsection{Application}

The hybrid optimization method solves the difficulty of solving multiple uncertainties, and makes the optimization strategy of IES meet the needs of real-time scheduling. Based on fuzzy and Monte Carlo simulation technology, the effect of intermittent renewable power generation on the active power loss of the distribution system is studied in (Soroudi, 2012). Dong et al. (2019) proposed a fuzzy-scenario hybrid method, taking into account the uncertainty of intermittent renewable power generation and variable load demand. In (Baghaee et al., 2017), a random-possibility method was proposed, using fuzzy set theory to manage the uncertainty in reliability input data, such as failure rate, maintenance time, and operation of protection devices. In (Jiang et al., 2020), considering the multiple uncertain characteristics of renewable energy generation and load forecast errors in the system, a hybrid optimization scheduling strategy based on interval-stochastic was proposed.

Each of the above uncertainty optimization methods has its focus, advantages and limitations. How to choose an appropriate uncertainty modeling method is shown in Figure 4. The characteristics of various uncertainty optimization methods are summarized in Table 3.

\subsection{Solution Method}

The uncertainty optimization model of the IES is more complicated. The main difficulties in solving the model are: 1) It is difficult to judge that the obtained solution is the global optimal solution; 2) The decision variables include integer variables and continuous variables; 3 ) The nonlinearity of the problem. The corresponding solving algorithms mainly include: analytical method, model reduction method, intelligent optimization algorithm, simulation software, etc.

\subsubsection{Analytical Method}

In order to make the model easy to solve, many studies use relaxation, convex optimization, dual theory, big $\mathrm{M}$ method, ADMM distributed algorithm and other technologies to approximate the original optimization problem to a linear programming (LP) problem or a mixed integer linear programming (MILP) problem. Alipour et al. (2015) divides the original non-convex feasible region of CHP into two independent convex regions, and realizes the convexity of the feasible region by adding binary variables and constraints. The coefficient of performance of the heat pump will change with changes in temperature. The second-order cone constraint and polyhedral constraint are used for linearization, and then solved by a commercial solver (Huang et al., 2019). The AC model used in the modeling of the distribution network will have nonlinear constraints. The branch-flow model is widely used, and slack variables are introduced to transform the original optimization problem into a second-order cone programming problem. The mass flow in the hydraulic process and the temperature of the supply and return water in the thermal process are variable, and the convexity technology can be used to deal with the nonlinear term according to the adopted thermal regulation mode. In addition, for minimax problems, Jiang et al. (2012), Zeng and Zhao (2013) use strong and weak duality theory to transform the original problem into an equivalent KKT condition or dual optimization problem with complementary constraints. The bilinear term generated by weak dual optimization is processed by the global optimal big- $\mathrm{M}$ method and the local optimal external approximation method. Zhang et al. (2021) established an IES optimal scheduling model based on twostage robust optimization, and used the ADMM algorithm to eliminate the non-convergence caused by binary variables.

\subsubsection{Model Reduction Method}

Model simplification and order reduction methods refer to the use of lower-order models to simulate higher-order models, which can maintain basic consistency with higher-order models in performance such as dynamic response. The commonly used reduction methods can be divided into the following categories: model simplification methods based on aggregate equivalence classes, model simplification methods based on time constants, and model reduction methods based on mathematical theories. The simplification method based on the aggregate equivalent class model is to convert a large number 


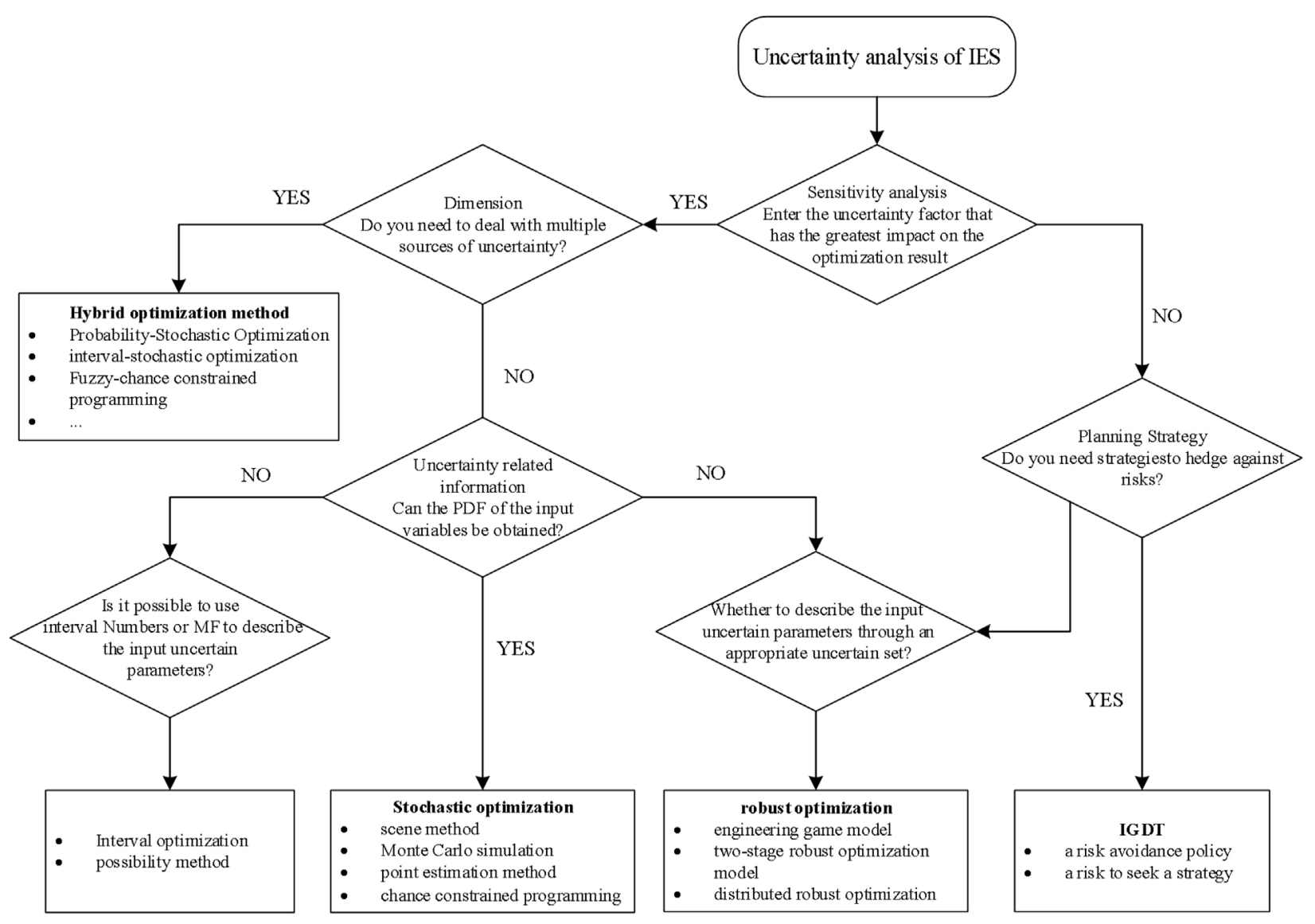

FIGURE 4 | How to choose uncertainty modeling method.

TABLE 3 | Summaries of uncertainty modeling attributes.

\begin{tabular}{|c|c|c|c|}
\hline Group & Main idea & Advantages & Disadvantages \\
\hline $\begin{array}{l}\text { Stochastic } \\
\text { optimization }\end{array}$ & $\begin{array}{l}\text { Use probability density functions. such as: scene } \\
\text { method, Monte Carlo simulation, point estimation } \\
\text { method, chance constrained programming }\end{array}$ & $\begin{array}{l}\text { Accurate, Simulation of the real world, } \\
\text { Good for big and complex problems }\end{array}$ & $\begin{array}{l}\text { Time consuming, High computational burden, } \\
\text { Execution time depends on the number of uncertain } \\
\text { variables }\end{array}$ \\
\hline $\begin{array}{l}\text { Robust } \\
\text { optimization }\end{array}$ & $\begin{array}{l}\text { Using uncertain sets, such as: engineering game model } \\
\text { two-stage robust optimization model and distributed } \\
\text { robust optimization model }\end{array}$ & Useful when just an interval exists & $\begin{array}{l}\text { Conservative decision, difficult to use in nonlinear } \\
\text { problems }\end{array}$ \\
\hline $\begin{array}{l}\text { Interval } \\
\text { optimization }\end{array}$ & Using intervals & Useful when just an interval exists & Cannot model the correlation between intervals \\
\hline $\begin{array}{l}\text { Possibilistic } \\
\text { method }\end{array}$ & Using fuzzy membership function & $\begin{array}{l}\text { Can obtain the membership function } \\
\text { of output variable }\end{array}$ & Time consuming, Cannot model correlation \\
\hline IGDT & Using forecasted values & $\begin{array}{l}\text { Useful for decision making in severe } \\
\text { uncertainties }\end{array}$ & Complexity \\
\hline $\begin{array}{l}\text { Hybrid } \\
\text { optimization }\end{array}$ & Modeling multiple uncertainties & $\begin{array}{l}\text { Can model the real world conditions, } \\
\text { model different uncertainties }\end{array}$ & Time consuming \\
\hline
\end{tabular}

of distributed power sources with close electrical distances into one or several equivalent models according to the similarity of their dynamic characteristics. Liao et al. (2018) proposed a coherence criterion based on the generalized Hamiltonian action. The equivalent model of this method still has a clear physical meaning and is suitable for highly electronic power systems. The simplified modeling method based on time constant analysis refers to combining components with similar time constants to form a simplified model of the time scale by analyzing the differences in the time constants of different equipment and loads. Xiao et al. (2015) analyzed the inertial time constants and system eigenvalues of some components in the inverter microgrid, and established its simplified model. Model reduction methods based on mathematical theory, such 


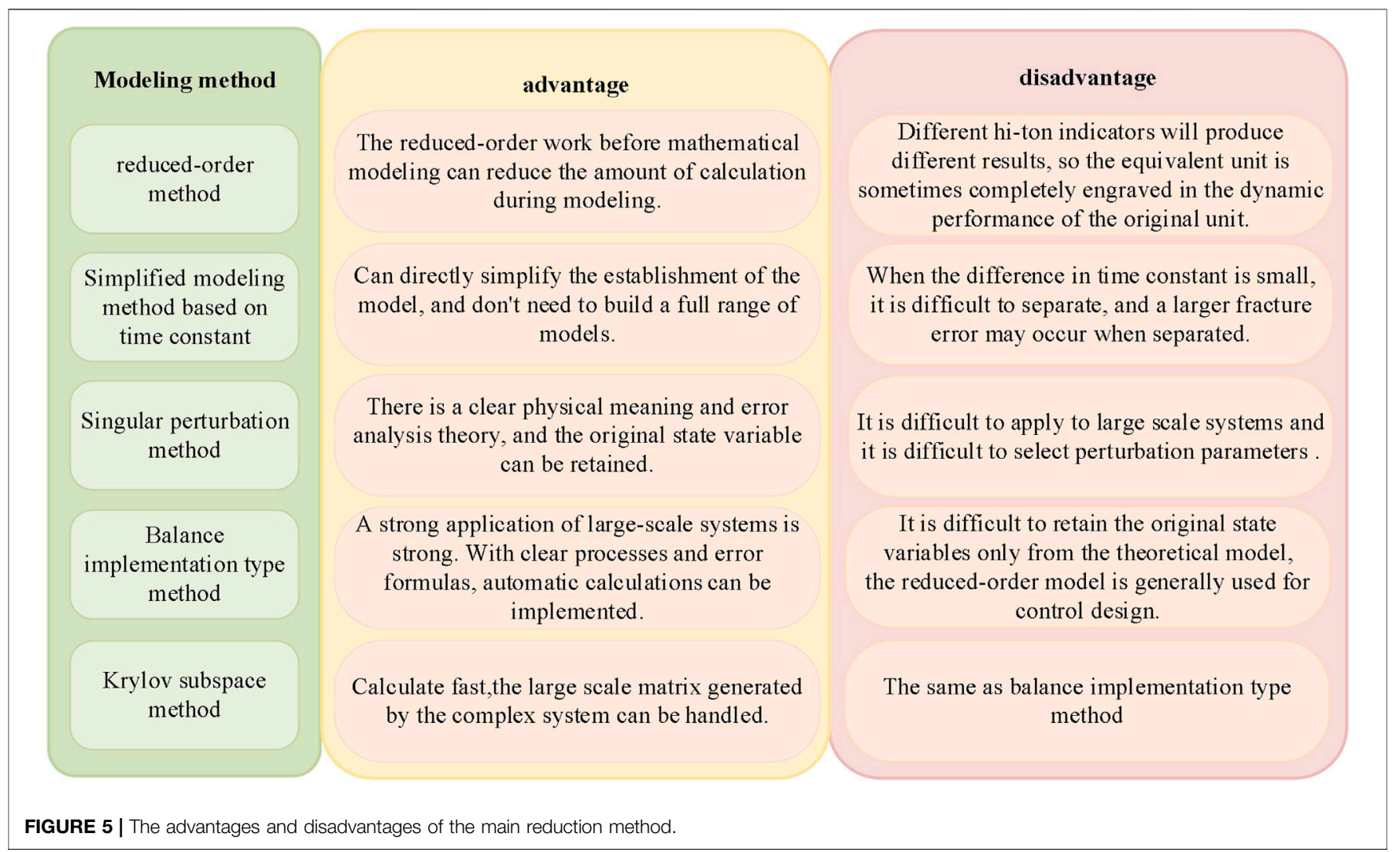

as: singular perturbation method, balance realization method, Krylov subspace method, etc. Zhu et al. (2016) proposed a largescale distribution network model simplification method based on the linear system simplification theory of Krylov subspace, which can improve the speed and efficiency of simulation calculation. The advantages and disadvantages of the main reduction method are shown in Figure 5.

\subsubsection{Intelligent Optimization Algorithm}

Intelligent algorithms can be used to solve the uncertain optimization operation problems of IES with nonlinear and non-convex characteristics, including genetic algorithm, particle swarm algorithm, simulated annealing algorithm, etc. The solution performance of the algorithms is usually compared according to indicators such as economic benefit, number of iterations, and calculation time. The use of traditional intelligent algorithms is more sensitive to initial conditions and controllable parameters, but still has the disadvantages of slow convergence, inability to meet online calculation requirements, and inability to guarantee the stability of the solution. With the development of artificial intelligence technology, machine learning methods such as reinforcement learning and deep learning are used to characterize the uncertainty of parameters. Such methods usually require a lot of historical data, and offline training takes a lot of time. At present, the related research of machine learning methods in IES decision-making is still in its infancy.

\subsubsection{Simulation Software}

In addition to using mathematical models to process uncertain factors, the actual engineering application is inseparable from the support of the simulation tools and platforms. Choosing suitable simulation tools is of great significance to the planning and optimization of IES. In order to facilitate the researcher to choose the appropriate simulation software, Table 4 summarizes the seven commonly used IES simulation tools.

\section{SUMMARY AND FUTURE WORK}

1) Uncertainty analysis: IES comprehensively covers various energy forms such as electricity, gas, heat, and cold. Its uncertainty and complexity far exceed any single system, and it may exist in all links of energy production, transmission, conversion, and consumption. Therefore, in addition to the uncertain factors mentioned in this article, other influencing factors, such as policy, political and social factors, need to be considered.

2) Uncertainty modeling method: There are many uncertain factors in IES, and a single uncertainty modeling method is often not accurate enough to deal with the impact of multiple uncertainties. A combination of different models should be considered for a comprehensive analysis to improve economic benefits. 
TABLE 4 | summarizes of seven commonly used IES simulation tools.

\begin{tabular}{|c|c|c|c|c|c|c|}
\hline Group & $\begin{array}{l}\text { Time } \\
\text { scale }\end{array}$ & Energy & $\begin{array}{l}\text { Energy } \\
\text { type }\end{array}$ & Energy storage & Simulation target & $\begin{array}{l}\text { User- } \\
\text { friendliness }\end{array}$ \\
\hline Simulink & Second & $\begin{array}{l}\text { Fossil energy, biomass, PV, Wind } \\
\text { power, hydrogen energy }\end{array}$ & $\begin{array}{l}\text { Electric, } \\
\text { hot, gas }\end{array}$ & $\begin{array}{l}\text { Battery, heat/cold/hydrogen } \\
\text { storage, AC, super capacitor } \\
\text { energy storage }\end{array}$ & $\begin{array}{l}\text { Instantaneous state of the } \\
\text { simulation system }\end{array}$ & Middle \\
\hline HOMER & Minute & Fossil energy, biomass, PV, Wind power & $\begin{array}{l}\text { Electric, } \\
\text { hot, cold }\end{array}$ & Battery, hydrogen storage & Minimum net cost & High \\
\hline TRNSYS & Second & $\begin{array}{l}\text { Fossil energy, biomass, PV, Wind } \\
\text { power, geothermal energy }\end{array}$ & $\begin{array}{l}\text { Electric, } \\
\text { hot, cold }\end{array}$ & $\begin{array}{l}\text { Battery, heat/cold/hydrogen } \\
\text { storageAC. }\end{array}$ & $\begin{array}{l}\text { Analog transient system } \\
\text { behavior }\end{array}$ & Middle \\
\hline Neplan & Second & $\begin{array}{l}\text { Fossil energy, biomass, } \mathrm{PV} \text {, wind power, } \\
\text { tidal energy }\end{array}$ & $\begin{array}{l}\text { Electric, } \\
\text { hot, gas }\end{array}$ & Battery, thermal storage & Optimization network layout & High \\
\hline DER-CAM & Minute & $\begin{array}{l}\text { Fossil energy, nuclear energy, biomass, } \\
\text { PV, geothermal energy }\end{array}$ & $\begin{array}{l}\text { Electric, } \\
\text { hot, cold }\end{array}$ & $\begin{array}{l}\text { Pumped energy storage, battery, } \\
\text { heat storageAC. }\end{array}$ & $\begin{array}{l}\text { Minimum cost of energy/ } \\
\text { CO2 emissions }\end{array}$ & Middle \\
\hline Polysun & Second & Wind power, PV, geothermal energy & Electric, hot & heat storage & $\begin{array}{l}\text { Detailed modeling of solar } \\
\text { and hydraulic systems }\end{array}$ & High \\
\hline EnergyPLAN & Hour & $\begin{array}{l}\text { Fossil energy, nuclear energy, biomass, } \\
\text { hydraulic power generation, PV, wind } \\
\text { power }\end{array}$ & Electric, hot & $\begin{array}{l}\text { Pumped energy storage, battery, } \\
\text { heat/hydrogen storage }\end{array}$ & $\begin{array}{l}\text { Technology, economically } \\
\text { optimization }\end{array}$ & High \\
\hline
\end{tabular}

3) Solution method: The nonlinear term or non-convex optimization of the uncertainty optimization problem can be dealt with by appropriate simplification or equivalent transformation. In addition, the dimensionality of the model is relatively high, and it is necessary to adopt a reduction method or develop a decomposition scheme that adapts to complex coupling constraints to improve the convergence speed. The intelligent optimization algorithm based on machine learning is still in its infancy and still needs further research.

\section{CONCLUSION}

In this article, we have conducted a comprehensive review of the main uncertainty categories and uncertainty modeling methods of IES optimization operations. First of all, the uncertainty categories are roughly divided into the uncertainty of renewable energy output, the uncertainty of equipment operating status and system status, the uncertainty of load forecasting, the uncertainty of mobile/virtual energy storage, the uncertainty of market rules/energy prices. Secondly, a comprehensive review of the main uncertainty modeling methods: probabilistic methods, robust optimization, interval optimization/probability methods, IGDT theory, and hybrid optimization methods, etc. One of the key points of this review is to find that the five uncertainty optimization methods have their respective focuses, advantages and limitations. Therefore, it is particularly important to choose a suitable uncertainty modeling method. First, we need to

\section{REFERENCES}

Aien, M., Hajebrahimi, A., and Fotuhi-Firuzabad, M. (2016). A Comprehensive Review on Uncertainty Modeling Techniques in Power System Studies. Renew. determine the availability of data and the uncertainty space covered. It is worth noting that the proposed modeling methods are not independent of each other, and a combination of different methods can be used for a more comprehensive analysis. Although it is generally believed that uncertainty is the key issue for IES optimization operation, our reference review results show that most optimization models are still deterministic. Therefore, when dealing with IES uncertain optimization problems, you can try to retain the key uncertain factors and ignore the less influential uncertain factors, thereby reducing the number of random variables in the uncertain optimization problem, reducing the difficulty of solving, and improving the solution Speed and efficiency. Future research on uncertainty modeling should also consider broader uncertainties, such as considering model structure, policy, political and social factors, etc., and exploring new methods to deal with these uncertainties.

\section{AUTHOR CONTRIBUTIONS}

$\mathrm{HF}$ and CW were responsible for writing the article, and LL and $\mathrm{XL}$ were responsible for the revision of the article.

\section{ACKNOWLEDGMENTS}

The authors would like to thank the members of the research team for their suggestions. The authors also thank the referees and the editor of this journal.

Sust. Energ. Rev. 57, 1077-1089. doi:10.1016/j.rser.2015.12.07010.1016/ j.rser.2015.12.070

Alipour, M., Mohammadi-Ivatloo, B., and Zare, K. (2015). Stochastic Scheduling of Renewable and CHP-Based Microgrids. IEEE Trans. Ind. Inf. 11, 1049-1058. doi:10.1109/TII.2015.2462296 
Baghaee, H. R., Mirsalim, M., Gharehpetian, G. B., and Talebi, H. A. (2017). Fuzzy Unscented Transform for Uncertainty Quantification of Correlated Wind/PV Microgrids: Possibilistic-Probabilistic Power Flow Based on RBFNNs. IET Renew. Power Generation 11, 867-877. doi:10.1049/iet-rpg.2016.0669

Cao, X., Wang, J., and Zeng, B. (2018). A Chance Constrained Information-Gap Decision Model for Multi-Period Microgrid Planning. IEEE Trans. Power Syst. 33, 2684-2695. doi:10.1109/tpwrs.2017.2747625

Chen, B., Sun, H., and Chen, Y. (2020). Energy Circuit Theory of Integrated Energy System Analysis (I): Gaseous Circuit. Proc. CSEE 40, 436-444. doi:10.13334/ j.0258-8013.pcsee.200028

Chen, S., Wei, Z., Sun, G., Cheung, K. W., and Sun, Y. (2017). Multi-Linear Probabilistic Energy Flow Analysis of Integrated Electrical and Natural-Gas Systems. IEEE Trans. Power Syst. 32, 1970-1979. doi:10.1109/ tpwrs.2016.2597162

Chen, W., Mu, Y., Jia, H., Wei, W., and He, W. (2020). Operation Optimization Method for Regional Integrated Energy System that Considers Part-Load Performances of Devices. Power Syst. Tech. 11, 1000-3673. doi:10.13335/ j.1000-3673.pst.2020.1149

Chen, Y., Wei, W., and Liu, F. (2018). CES Utility Function Based Consumer Optimal Decision Making in Heat-Power Market. Automation Electric Power Syst. 42, 118-126. doi:10.7500/AEPS20171225004

Chen, Z., Sun, Y., Xin, A., Majeed Malik, S., and Yang, L. (2020). Integrated Demand Response Characteristics of Industrial Park: A Review. J. Mod. Power Syst. Clean Energ. 8, 15-26. doi:10.35833/mpce.2018.000776

Clegg, S., and Mancarella, P. (2016). Integrated Electrical and Gas Network Flexibility Assessment in Low-Carbon Multi-Energy Systems. IEEE Trans. Sustain. Energ. 7, 718-731. doi:10.1109/tste.2015.2497329

Dai, Q., Duan, S., and Cai, T. (2011). Short-term PV Generation System Forecasting Model without Irradiation Based on Weather Type Clustering. Proc. CSEE 31, 28-35. doi:10.13334/j.0258-8013.pcsee.2011.34.026

Dai, R., Esmaeilbeigi, R., and Charkhgard, H. (2021). The Utilization of Shared Energy Storage in Energy Systems: A Comprehensive Review. IEEE Trans. Smart Grid 12, 3163-3174. doi:10.1109/TSG.2021.3061619

Dantzig, G. (1955). Linear Programming under Uncertainty. ManagSci 1, 197-206. doi:10.1287/mnsc.1.3-4.197

Deng, S., Wu, Q., Jing, Z., WuWei, L. F., Wei, F., and Zhou, X. (2017). Optimal Capacity Configuration for Energy Hubs Considering Part-Load Characteristics of Generation Units. Energies 10, 1966. doi:10.3390/en10121966

Ding, Y., Cheng, L., Zhang, Y., and Xue, Y. (2014). Operational Reliability Evaluation of Restructured Power Systems with Wind Power Penetration Utilizing Reliability Network Equivalent and Time-Sequential Simulation Approaches. J. Mod. Power Syst. Clean. Energ. 2, 329-340. doi:10.1007/ s40565-014-0077-8

Ding, Y., Singh, C., Goel, L., Ostergaard, J., and Wang, P. (2014). Short-term and Medium-Term Reliability Evaluation for Power Systems with High Penetration of Wind Power. IEEE Trans. Sustain. Energ. 5, 896-906. doi:10.1109/ TSTE.2014.2313017

Doan, A. T., Viet, D. T., and Duong, M. Q. (2021). Economic Load Dispatch Solutions Considering Multiple Fuels for thermal Units and Generation Cost of Wind Turbines. Int. J. Electr. Comput. Eng. 11, 3718-3726. doi:10.11591/ ijece.v1li5

Dolatabadi, A., Jadidbonab, M., and Mohammadi-ivatloo, B. (2019). Short-Term Scheduling Strategy for Wind-Based Energy Hub: A Hybrid Stochastic/IGDT Approach. IEEE Trans. Sustain. Energ. 10, 438-448. doi:10.1109/ TSTE.2017.2788086

Dong, H., Yun, Y., Ma, Z., and Wang, D. (2020). Low-carbon Optimal Operation of Integrated Energy System Considering Multi-Energy Conversion and Concentrating Solar Power Plant Participation. Power Syst. Tech. 44, 3689-3700. doi:10.13335/j.1000-3673.pst.2020.0449

Dong, Q., Sun, Q., Huang, Y., Li, Z., and Cheng, C. (2019). Hybrid PossibilisticProbabilistic Energy Flow Assessment for Multi-Energy Carrier Systems. IEEE Access 7, 176115-176126. doi:10.1109/access.2019.2943998

Edenhofer, O., Lessmann, K., Kemfert, C., Grubb, M., and Köhler, J. (2006). Induced Technological Change: Exploring its Implication for the Ecnomics of Atmospheric Stabilization. Energy. J. SI2006, 57-107. doi:10.5547/issn01956574-ej-volsi2006-nosi1-3

Fang, S., Zhao, T., Xu, Y., and Lu, T. (2020). Coordinated Chance-Constrained Optimization of Multi-Energy Microgrid System for Balancing Operation
Efficiency and Quality-Of-Service. J. Mod. Power Syst. Clean Energ. 8, 853-862. doi:10.35833/MPCE.2019.000466

Fang, X., Hodge, B.-M., Bai, L., Cui, H., and Li, F. (2018). Mean-Variance Optimization-Based Energy Storage Scheduling Considering Day-Ahead and Real-Time LMP Uncertainties. IEEE Trans. Power Syst. 33, 7292-7295. doi:10.1109/TPWRS.2018.2852951

Farzin, H., Ghorani, R., Fotuhi-Firuzabad, M., and Moeini-Aghtaie, M. (2019). A Market Mechanism to Quantify Emergency Energy Transactions Value in a Multi-Microgrid System. IEEE Trans. Sustain. Energ. 10, 426-437. doi:10.1109/ TSTE.2017.2741427

Guo, X., Gong, R., Bao, H., and Wang, Q. (2019). Hybrid Stochastic and Interval Power Flow Considering Uncertain Wind Power and Photovoltaic Power. IEEE Access 7, 85090-85097. doi:10.1109/access.2019.2924436

Hannan, M. A., Islam, N. N., Mohamed, A., Lipu, M. S. H., Ker, P. J., Rashid, M. M., et al. (2018). Artificial Intelligent Based Damping Controller Optimization for the Multi-Machine Power System: A Review. IEEE Access 6, 39574-39594. doi:10.1109/ACCESS.2018.2855681

He, C., Zhang, X., Liu, T., and Wu, L. (2019). Distributionally Robust Scheduling of Integrated Gas-Electricity Systems with Demand Response. IEEE Trans. Power Syst. 34, 3791-3803. doi:10.1109/tpwrs.2019.2907170

Hong, B., Zhang, W., Zhou, Y., Chen, J., Xiang, Y., and Mu, Y. (2018). EnergyInternet-oriented Microgrid Energy Management System Architecture and its Application in China. Appl. Energ. 228, 2153-2164. doi:10.1016/ j.apenergy.2018.07.081

Huang, S., Tang, W., Wu, Q., and Li, C. (2019). Network Constrained Economic Dispatch of Integrated Heat and Electricity Systems through Mixed Integer Conic Programming. Energy 179, 464-474. doi:10.1016/j.energy.2019.05.041

Huang, W., Zhang, N., and Wang, Y. (2020). Matrix Modeling of Energy Hub with Variable Energy Efficiencies. Int. J. Electr. Power Energ. Syst. 119, 105876. doi:10.1016/j.ijepes.2020.105876

Jiang, R., Wang, J., and Guan, Y. (2012). Robust Unit Commitment with Wind Power and Pumped Storage Hydro. IEEE Trans. Power Syst. 27, 800-810. doi:10.1109/TPWRS.2011.2169817

Jiang, Y., Wan, C., Chen, C., Shahidehpour, M., and Song, Y. (2020). A Hybrid Stochastic-Interval Operation Strategy for Multi-Energy Microgrids. IEEE Trans. Smart Grid 11, 440-456. doi:10.1109/tsg.2019.2923984

Kong, W., Dong, Z. Y., Hill, D. J., Luo, F., and Xu, Y. (2018). Short-Term Residential Load Forecasting Based on Resident Behaviour Learning. IEEE Trans. Power Syst. 33, 1087-1088. doi:10.1109/tpwrs.2017.2688178

Lei, H., and Singh, C. (2017). Non-sequential Monte Carlo Simulation for CyberInduced Dependent Failures in Composite Power System Reliability Evaluation. IEEE Trans. Power Syst. 32, 1064-1072. doi:10.1109/ TPWRS.2016.257215910.1109/ptc.2017.7981165

Lei, H., Singh, C., and Sprintson, A. (2014). Reliability Modeling and Analysis of IEC 61850 Based Substation protection Systems. IEEE Trans. Smart Grid 5, 2194-2202. doi:10.1109/TSG.2014.2314616

Li, Q., Wang, L., Zhang, Y., Li, Y., and Xu, J. (2020). A Review of Coupling Models and Dynamic Optimization Methods for Energy Internet Multi-Energy Flow. Power Syst. Prot. Control. 48, 179-186. doi:10.19783/j.cnki.pspc.191309

Li, Z., Xu, Y., Fang, S., Zheng, X., and Feng, X. (2020). Robust Coordination of a Hybrid AC/DC Multi-Energy Ship Microgrid with Flexible Voyage and Thermal Loads. IEEE Trans. Smart Grid 11, 2782-2793. doi:10.1109/ TSG.2020.2964831

Li, Z., Xu, Y., Feng, X., and Wu, Q. (2021). Optimal Stochastic Deployment of Heterogeneous Energy Storage in a Residential Multienergy Microgrid with Demand-Side Management. IEEE Trans. Ind. Inf. 17, 991-1004. doi:10.1109/ TII.2020.2971227

Liao, S., Zha, X., Huang, M., Sun, J., and Hu, W. (2018). Coherency Criterion Applicable to Power Electronics Dominated Large Power Systems. Proc. CSEE 38, 0258-8013. doi:10.13334/j.0258-8013.pcsee.170388

Liu, G., Starke, M., Xiao, B., Zhang, X., and Tomsovic, K. (2017). Microgrid Optimal Scheduling with Chance-Constrained Islanding Capability. Electric Power Syst. Res. 145, 197-206. doi:10.1016/j.epsr.2017.01.014

Liu, H., Tian, S., Wang, X., Cao, Y., Zeng, M., and Li, Y. (2021). Optimal Planning Design of a District-Level Integrated Energy System Considering the Impacts of Multi-Dimensional Uncertainties: A Multi-Objective Interval Optimization Method. IEEE Access 9, 26278-26289. doi:10.1109/ACCESS.2021.3053598 
Liu, P., Fu, Y., and Kargarian marvasti, A. (2014). Multi-stage Stochastic Optimal Operation of Energy-Efficient Building with Combined Heat and Power System. Electric Power Components Syst. 42, 327-338. doi:10.1080/15325008.2013.862324

Liu, Y., Sun, Y., Infield, D., Zhao, Y., Han, S., and Yan, J. (2017). A Hybrid Forecasting Method for Wind Power Ramp Based on Orthogonal Test and Support Vector Machine (OT-SVM). IEEE Trans. Sustain. Energ. 8, 451-457. doi:10.1109/TSTE.2016.2604852

Lu, S., Gu, W., Meng, K., Yao, S., Liu, B., and Dong, Z. (2019). Thermal Inertial Aggregation Model for Integrated Energy Systems. IEEE Trans. Power Syst. 35, 2374-2387. doi:10.1109/TPWRS.2019.2951719

Lu, S., Gu, W., Zhou, S., Yao, S., and Pan, G. (2020). Adaptive Robust Dispatch of Integrated Energy System Considering Uncertainties of Electricity and Outdoor Temperature. IEEE Trans. Ind. Inf. 16, 4691-4702. doi:10.1109/TII.2019.2957026

Mamun, A. A., Sohel, M., Mohammad, N., Haque Sunny, M. S., Dipta, D. R., and Hossain, E. (2020). A Comprehensive Review of the Load Forecasting Techniques Using Single and Hybrid Predictive Models. IEEE Access 8, 134911-134939. doi:10.1109/ACCESS.2020.3010702

Mei, S., Guo, W., and Wang, Y. (2013). A Game Model for Robust Optimization of Power Systems and its Application. Proc. CSEE 33, 47-56. doi:10.13334/j.02588013.pcsee.2013.19.001

Oh, U., Lee, Y., Choi, J., and Karki, R. (2020). Reliability Evaluation of Power System Considering Wind Generators Coordinated with Multi-energy Storage Systems. IET Generation, Transm. Distribution 14, 786-796. doi:10.1049/ietgtd.2018.6071.s10.1049/iet-gtd.2018.6071

Qadrdan, M., Wu, J., Jenkins, N., and Ekanayake, J. (2014). Operating Strategies for a GB Integrated Gas and Electricity Network Considering the Uncertainty in Wind Power Forecasts. IEEE Trans. Sustain. Energ. 5, 128-138. doi:10.1109/ TSTE.2013.2274818

Rassaei, F., Soh, W.-S., and Chua, K.-C. (2018). Distributed Scalable Autonomous Market-Based Demand Response via Residential Plug-In Electric Vehicles in Smart Grids. IEEE Trans. Smart Grid 9, 3281-3290. doi:10.1109/ TSG.2016.262951510.1109/tsg.2016.2629515

Roldán, C., Mínguez, R., García-Bertrand, R., and Arroyo, J. (2019). Robust Transmission Net-Work Expansion Planning under Correlated Uncertainty. IEEE Trans. Power Syst. 34, 2071-2082. doi:10.1109/tpwrs.2018.2889032

Shahidinejad, S., Filizadeh, S., and Bibeau, E. (2012). Profile of Charging Load on the Grid Due to Plug-In Vehicles. IEEE Trans. Smart Grid 3, 135-141. doi:10.1109/TSG.2011.2165227

Si, C., Xu, S., Wan, C., Chen, D., Cui, W., and Zhao, J. (2020). Electric Load Clustering in Smart Grid: Methodologies, Applications, and Future Trends. J. Mod. Power Syst. Clean Energ. 9, 237-252. doi:10.35833/MPCE.2020.000472

Soroudi, A. (2012). Possibilistic-Scenario Model for DG Impact Assessment on Distribution Networks in an Uncertain Environment. IEEE Trans. Power Syst. 27, 1283-1293. doi:10.1109/tpwrs.2011.2180933

Soyster, A. L. (1973). Technical Note-Convex Programming with Set-Inclusive Constraints and Applications to Inexact Linear Programming. Operations Res. 21, 1154-1157. doi:10.1287/opre.21.5.1154

Su, Y., Nie, W., Zhou, Y., Tan, M., and Qiao, H. (2017). “An Interval Based CostEmissions Optimization Strategy for Gas-Electricity Integrated Energy Systems under Uncertainty and Demand Response," in IEEE Conference on Energy Internet and Energy System Integration (EI2), Beijing, China, November 26-28, 2017, 1-6. doi:10.1109/EI2.2017.8245525

Sun, G., Chen, S., Wei, Z., and Chen, S. (2017). Multi-period Integrated Natural Gas and Electric Power System Probabilistic Optimal Power Flow Incorporating Power-To-Gas Units. J. Mod. Power Syst. Clean. Energ. 5, 412-423. doi:10.1007/s40565-017-0276-1

Sun, H., Guo, Q., and Pan, Z. (2015). Energy Internet: Concept, Architecture, and Frontier Outlook. Automation Electric Power Syst. 39, 1-8. doi:10.7500/ AEPS20150701007

Sun, J., Wei, Z., and Sun, G. (2017). Analysis of Probabilistic Energy Flow for Integrated Electricity-Heat Energy System with P2H. Electric Power Automation Equipment 37, 62-68. doi:10.16081/j.issn.1006-6047.2017.06.009

Tuan, L., Duong, M. Q., Sava, G. N., and Tanasiev, V. (2020). Optimization of Renewable Energy Sources Operation in Vietnams Electricity Market. Revue Roumaine des. Sci. Tech. 65, 221-227.

U.S. Department of Energy (2019). U.S. Energy Information Administration. Annual Energy Outlook 2019. Available at: http://www.eia.gov/outlooks/aeo/ pdf/aeo2019.pdf.
Vahabzad, N., Jadidbonab, M., Mohammadi-Ivatloo, B., Tohidi, S., and AnvariMoghaddam, A. (2020). Energy Management Strategy for a Short-route Hybrid Cruise Ship: an IGDT-based Approach. IET Renew. Power Generation 14, 1755-1763. doi:10.1049/iet-rpg.2019.0882

Valencia, F., Collado, J., Saez, D., and Marin, L. G. (2016). Robust Energy Management System for a Microgrid Based on a Fuzzy Prediction Interval Model. IEEE Trans. Smart Grid 7, 1486-1494. doi:10.1109/ TSG.2015.2463079

Wang, C., Gao, R., Wei, W., Shafie-khah, M., Bi, T., and Catalao, J. P. S. (2019). Risk-Based Distributionally Robust Optimal Gas-Power Flow with Wasserstein Distance. IEEE Trans. Power Syst. 34, 2190-2204. doi:10.1109/ TPWRS.2018.2889942

Wang, Y., Cheng, J., Zhang, N., and Kang, C. (2018). Automatic and Linearized Modeling of Energy Hub and its Flexibility Analysis. Appl. Energ. 211, 705-714. doi:10.1016/j.apenergy.2017.10.125

Wang, Y., Xia, Q., and Kang, C. (2011). Secondary Forecasting Based on Deviation Analysis for Short-Term Load Forecasting. IEEE Trans. Power Syst. 26, 500-507. doi:10.1109/TPWRS.2010.2052638

Wang, Y., Zhang, N., Kang, C., Kirschen, D. S., Yang, J., and Xia, Q. (2019). Standardized Matrix Modeling of Multiple Energy Systems. IEEE Trans. Smart Grid 10, 257-270. doi:10.1109/TSG.2017.2737662

Wei, D., Zhang, C., and Sun, B. (2015). Economic Optimal Operation of Micro Combined Cooling Heating and Power System Considering Off-Design Performance. Power Syst. Tech. 39, 3240-3246. doi:10.13335/j.10003673.pst.2015.11.034

Wu, J., Zeng, C., and Miao, H. (2020). Economic Dispatch of Integrated Energy System Based on Chance-Constrained Goal Programming. Electric Power Construction 41, 47-54. doi:10.12204/j.issn.1000-7229.2020.12.005

$\mathrm{Wu}, \mathrm{L}$, Li, Z., Xu, Y., and Zheng, X. (2021). Stochastic-Weighted Robust Optimization Based Bi-layer Operation of A Multi-Energy Home Considering Practical Thermal Loads and Battery Degradation. IEEE Trans. Sustain. Energ. doi:10.1109/TSTE.2021.3126776

Xi, L., Yu, L., Xu, Y., Wang, S., and Chen, X. (2020). A Novel Multi-Agent DDQNAD Method-Based Distributed Strategy for Automatic Generation Control of Integrated Energy Systems. IEEE Trans. Sustain. Energ. 11, 2417-2426. doi:10.1109/TSTE.2019.2958361

Xiao, Z., Zhao, Q., and Fan, H. (2015). Analysis and Establishment of State-Space Equations for Inverter-Interfaced Microgrid. Automation Electric Power Syst. 39, 39-45. doi:10.7500/AEPS20140401008

Xu, F., Hao, L., Chen, L., Chen, Q., and Min, Y. (2021). Review of District Energy Network Dynamic Modeling and Coordinate Optimal Operation in Integrated Electricity and Heat Energy Systems. J. Glob. Energ. Interconnection 4, 55-63. doi:10.19705/j.cnki.issn2096-5125.2021.01.008

Xu, M., and Chen, F. (2021). Day-ahead Economic Dispatch Study of the Integrated Heat-Electricity-Gas Energy System Based on Data-Driven Distributionally Robust Optimization. Proc. CSU-EPSA 12, 1003-8930. doi:10.19635/j.cnki.csu-epsa.000763

Xu, Z., Sun, H., and Guo, Q. (2018). Review and prospect of Integrated Demand Response. Proc. CSEE 38, 7194-7205. doi:10.13334/j.0258-8013.pcsee.180893

Yao, Z., and Wang, Z. (2020). Two-level Collaborative Optimal Allocation Method of Integrated Energy System Considering Wind and Solar Uncertainty. Power Syst. Tech. 44, 1000-3673. doi:10.13335/j.1000-3673.pst.2020.0853

Zadeh, L. A. (1999). Fuzzy Sets as a Basis for a Theory of Possibility. Fuzzy Sets Syst. 100, 9-34. doi:10.1016/s0165-0114(99)80004-9

Zeng, B., and Zhao, L. (2013). Solving Two-Stage Robust Optimization Problems Using a Column-And- Constraint Generation Method. Operations Res. Lett. 41 , 457-461. doi:10.1016/j.orl.2013.05.003

Zhang, L., Tang, W., Liang, J., Cong, P., and Cai, Y. (2016). Coordinated DayAhead Reactive Power Dispatch in Distribution Network Based on Real Power Forecast Errors. IEEE Trans. Power Syst. 31, 2472-2480. doi:10.1109/ TPWRS.2015.2466435

Zhang, S., Miao, S., Yang, W., Liu, Z., and Wang, P. (2021). Distributed Robust Optimal Dispatch for Active Distribution Networks Based on Alternative Direction Method of Multipliers with Dynamic Step Size. High Voltage Eng. 47, 81-93. doi:10.13336/j.1003-6520.hve.20201180

Zhang, Y., Le, J., Zheng, F., Zhang, Y., and Liu, K. (2019). Two-stage Distributionally Robust Coordinated Scheduling for Gas-Electricity Integrated Energy System Considering Wind Power Uncertainty and reserve 
Capacity Configuration. Renew. Energ. 135, 122-135. doi:10.1016/ j.renene.2018.11.094

Zhao, B., Conejo, A. J., and Sioshansi, R. (2017). Unit Commitment under GasSupply Uncertainty and Gas-Price Variability. IEEE Trans. Power Syst. 32, 2394-2405. doi:10.1109/TPWRS.2016.2602659

Zhao, J., Wan, C., Xu, Z., and Wang, J. (2017). Risk-Based Day-Ahead Scheduling of Electric Vehicle Aggregator Using Information Gap Decision Theory. IEEE Trans. Smart Grid 8, 1609-1618. doi:10.1109/ tsg.2015.2494371

Zhao, P., Gu, C., Huo, D., Shen, Y., and Hernando-Gil, I. (2019). TwoStage Distributionally Robust Optimization for Energy Hub Systems. IEEE Trans. Ind. Inform. 16, 3460-3469. doi:10.1109/ TII.2019.2938444

Zhong, Y., Huang, M., and Qiang, D. (2013). Reliability Modeling of Battery Energy Storage System and its Effect on the Reliability of Distribution System. Power Syst. Prot. Control. 41, 95-102.

Zhou, H., Li, Z., Zheng, J. H., Wu, Q. H., and Zhang, H. (2020). Robust Scheduling of Integrated Electricity and Heating System Hedging Heating Network Uncertainties. IEEE Trans. Smart Grid 11, 1543-1555. doi:10.1109/ TSG.2019.2940031

Zhu, Z., Geng, G., and Jiang, Q. (2016). Power System Dynamic Model Reduction Based on Extended Krylov Subspace Method. IEEE Trans. Power Syst. 31, 4483-4494. doi:10.1109/TPWRS.2015.2509481
Zugno, M., Morales, J. M., and Madsen, H. (2016). Commitment and Dispatch of Heat and Power Units via Affinely Adjustable Robust Optimization. Comput. Operations Res. 75, 191-201. doi:10.1016/j.cor.2016.06.002

Conflict of Interest: XL was employed by the company State Grid Economic and Technological Research Institute Co., Ltd.

The remaining authors declare that the research was conducted in the absence of any commercial or financial relationships that could be construed as a potential conflict of interest.

Publisher's Note: All claims expressed in this article are solely those of the authors and do not necessarily represent those of their affiliated organizations, or those of the publisher, the editors and the reviewers. Any product that may be evaluated in this article, or claim that may be made by its manufacturer, is not guaranteed or endorsed by the publisher.

Copyright (C) 2022 Fan, Wang, Liu and Li. This is an open-access article distributed under the terms of the Creative Commons Attribution License (CC BY). The use, distribution or reproduction in other forums is permitted, provided the original author(s) and the copyright owner(s) are credited and that the original publication in this journal is cited, in accordance with accepted academic practice. No use, distribution or reproduction is permitted which does not comply with these terms. 